\title{
An Empirical Analysis for Mode Choice in a Short-Distance Trip with Personal Rapid Transit
}

\author{
Hyunmyung Kim, ${ }^{1}$ Haneum Seok, ${ }^{2}$ Soyoung Iris You $\mathbb{D}^{\mathrm{D}},{ }^{3}$ and Changju Lee $\mathbb{D}^{4}$ \\ ${ }^{1}$ Department of Transportation Engineering, Myongi University, Yongin 17058, Republic of Korea \\ ${ }^{2}$ Hanam Police Station, Gyeonggi Nambu Province Policy Agency, Hanam 13024, Republic of Korea \\ ${ }^{3}$ Innovative Transport Policy Division, Korea Railroad Research Institute, Uiwang 16105, Republic of Korea \\ ${ }^{4}$ Virginia Transportation Research Council, Charlottesville, VA 22903, USA \\ Correspondence should be addressed to Changju Lee; cl8ax@virginia.edu
}

Received 21 January 2020; Revised 2 September 2020; Accepted 5 October 2020; Published 17 November 2020

Academic Editor: Prakash Ranjitkar

Copyright $\odot 2020$ Hyunmyung Kim et al. This is an open access article distributed under the Creative Commons Attribution License, which permits unrestricted use, distribution, and reproduction in any medium, provided the original work is properly cited.

\begin{abstract}
Recently, there have been emerging demands for new transportation modes, such as personal rapid transit (PRT), to improve the connectivity of first and last mile travel. Advancement of ICT and growing concerns over environmental issues reinforce such demands through which specific transportation modes can satisfy the need of each individual for shortdistance trips. Although PRT has received particular attention for short-distance trips, it is true that recent approaches have been developed to analyze the behavior of travelers for mid- to long-distance trips that are not relevant for short-distance trips. This study proposed a suitable approach using logistic regression models that could assist the understanding of features which determine mode choice in a short-distance trip. The mode choice for PRT in short-distance trips in this study was based on the data from the survey. After considering various factors, it was apparent that the purpose of the trip together with weather conditions impacted significantly on travelers' mode choices to PRT in short-distance trips. Additionally, it is expected that this study will play an important initial role in analyzing emerging transportation modes that can more easily respond to new demands for short-distance trips.
\end{abstract}

\section{Introduction}

In the four-step travel demand modeling process, mode choice models compute the proportion of trips that use a specific transportation mode between each origin and destination estimated from the trip distribution step. The capacity to explain the mode choice models following the introduction of a new mode or improvement of transportation service directly affects the accuracy of estimated trips by each mode, e.g., [1-3]. Mode choice models, consequently, play a critical role in decisions about investments in transportation [4].

Most current mode choice models target inter- or intraregional travel of mid/long-distance trips. The assessment of investments or plans for transportation infrastructure, considering the movement of transportation modes separately and commonly, does not include the entire trip of travelers.
Consequently, travel distance and/or time of each transportation mode (e.g., automobile, rail, bus, subway, and taxi) have been employed as significant factors that are suggested to be implemented from previous studies, e.g., $[2,3,5,6]$.

The advent of a new user-oriented paradigm requires that traditional supply-oriented transportation services are changed to user-centered ones. Concurrently, road infrastructure for mid/long-distance trips in many metropolitan cities has already reached the maturity stage. A novel approach of smart mobility using small-sized modes for the short-distance trip has been gaining in popularity. Environmental issues arising from traffic problems linked to the Paris Agreement [7] have created a new social norm to deliver a convenient, healthy, and sustainable society, with interest in special transportation modes for short-distance trips. A short-distance trip requires analyzing new factors 
including the level of service by public transportation, which have not been conducted due in part to the lack of suitable models or usable data [8].

The short-distance refers to a walkable distance on which walking, motorcycling, and bicycling currently comprise the major transportation modes. Travel of less than one $\mathrm{km}$ has often been ignored even in the short-distance trip. Recently, in tandem with the development of information and communication technologies, new transportation modes such as electric scooters, and autonomous and demandresponsive personal rapid transit (PRT) have also arisen as a means of a short-distance trip. These modes are key to connecting the terminal points of mid/long-distance trips by subways or buses, and to link the first and last miles to origins and destinations $[9,10]$. Thus, transportation modes for short-distance trips enhance seamless services, user satisfaction, and popularity of mass transit systems.

Transportation modes for short-distance trips are increasing in importance. However, traditional travel demand models have difficulty in explaining the impact of such trips [8]. Because current transportation systems allow free transfers and easy alighting and boarding, this limitation hinders reliable analysis of contemporary transportation techniques and policies. As most mode choice models have been developed for mid/long-distance trips, e.g., [11, 12], factors other than travel time and cost have been rationally neglected that have minor impacts on mode choice. However, the impact of other factors is significant as the traveler's time and cost is trivial in a short-distance trip. Examples include accessibility to terminals, discomfort of using stairs, adverse weather conditions, requirements of children/the elderly, and carrying of baggage. As previously mentioned, traditional mode choice approaches based the disaggregated behavioral models used in the four-step travel demand process are limited to fundamentally reflect these factors [8].

\section{Scope and Objectives}

The main objectives of this study are to identify and quantify factors affecting mode choice and, to provide fundamentals for the analysis of emerging transportation modes for the new demands of a short-distance trip. As a primary approach, a survey was conducted for inputs to identify the likely PRT choice considering the trip purpose, weather condition, and if passengers were accompanied by children. Here, the concept of PRT, one of desirable transportation modes, was used in this study as a competitive means of walking in a short-distance trip. To ascertain the objectives of this study, a literature review was conducted to identify a suitable methodology for the assessment. An analysis was then performed resulting in an updated interpretation.

\section{Literature Review}

This study is among initial attempts to understand factors that determine transportation modes in a short-distance trip and three points are of major interest in the literature review which include

(1) defining of the range of a short-distance trip;
(2) alternative modes considered for a short-distance trip; and

(3) explaining variables that determine the transportation modes for a particular short-distance trip.

3.1. Range Definition for the Short-Distance Trip. Travel distance is the most influential factor in determining a transportation mode. For example, the airplane is preferable for distances over $1,000 \mathrm{~km}$, whereas walking, motorcycling, or cycling is a reasonable choice for distances less than $2 \mathrm{~km}$. To develop mode choice models for a short-distance trip, the range of distance is therefore required to be defined for this study.

As shown in Table 1, although $5 \mathrm{~km}$ was frequently used as the maximum boundary for the short-distance trip $[15,16]$, various definitions of the short-distance trip have been suggested recently. That is, it is noted that a distance of less than $3 \mathrm{~km}$ was adopted in the most recent study [17] in order to respond to the need for the analysis of nonmotorized trips such as walking and bicycles.

3.2. Mode Alternatives for a Short-Distance Trip. Even for a short-distance trip, travelers frequently determine their travel from a specific set of available modes clustered by travel distance. For example, in Shanghai, China (see Figure 1), differences in average travel distance determined which mode was chosen for the short-distance trip. For example, walking was selected for an average travel distance of $1 \mathrm{~km}$, while motorized modes (i.e., scooter and bus) were taken above an average travel distance of $2 \mathrm{~km}$.

In addition to the preferred travel mode by distance, the average travel distance of all short-distance trip modes of 1.687 meters was used as a reference for the range of shortdistance trips in this study.

To develop suitable mode choice models, possible alternative modes for a short-distance trip need to be explored which are shown in Table 2.

From the literature review, walking is the most prevalent mode for a short-distance trip (11 out of 11), followed by cycling (10 out of 11), individual vehicles (8 out of 11), and buses ( 7 out of 11). Interestingly, the competitor to nonmotorized modes (i.e., walking and cycling) is not public transportation such as bus, but rather, individual vehicles. This means that for a short-distance trip, the use of individual vehicles is common because of their superior access and comfort. In other words, travelers favor their personal vehicle as competitive for the first and last mile as it also satisfies their need for access and comfort.

Comparing the number of considered modes from the previous literature shows the range that is a maximum of 7 , a minimum of 2, and an average of 4 . Thus, in general, four separate mode choices were considered for the short-distance trip.

3.3. Explanatory Variables for Mode Choice in a Short-Distance Trip. Table 3 outlines the variables reviewed for mode choice models for a short-distance trip from the previous literature. 
TABle 1: A comparison of definitions used for a short-distance trip.

\begin{tabular}{|c|c|c|}
\hline Authors & $\begin{array}{c}\text { Used } \\
\text { distance }\end{array}$ & Reasons \\
\hline $\begin{array}{l}\text { Kim and Ulfarsson } \\
{[13]}\end{array}$ & $\begin{array}{c}\text { Below } \\
2.25 \mathrm{~km}\end{array}$ & $\begin{array}{c}\text { A short-distance was defined by the } 95^{\text {th }} \text { percentile of walking distances on the basis of } 12,900 \text { trip data } \\
\text { sets }\end{array}$ \\
\hline Tran et al. [14] & Below $1 \mathrm{~km}$ & $\begin{array}{c}\text { A distance under } 1 \mathrm{~km} \text { was regarded as a short-distance because of its competitiveness for walking } \\
\text { rather than other modes, such as motorcycles and bicycles }\end{array}$ \\
\hline Li et al. [15] & Below $5 \mathrm{~km}$ & $\begin{array}{l}\text { A distance under } 5 \mathrm{~km} \text { was considered as a short-distance because of the majority, being over } 40 \% \text { of } \\
\text { all trips, caused traffic congestion }\end{array}$ \\
\hline $\mathrm{Pu}$ et al. [16] & Below $5 \mathrm{~km}$ & A distance under $5 \mathrm{~km}$ accounted for $90 \%$ of all short-distance trips for the elderly \\
\hline Ferrer and Ruiz [17] & Below $3 \mathrm{~km}$ & A short-distance was defined as the distance taking 45 minutes on foot or less \\
\hline
\end{tabular}

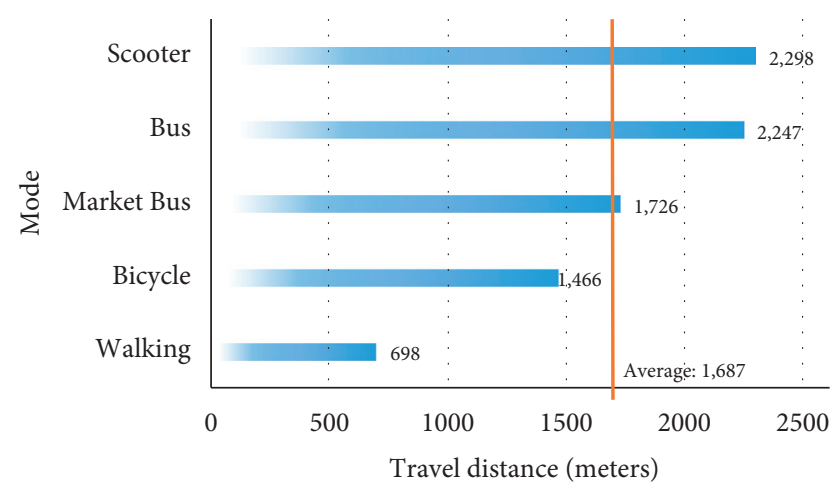

Figure 1: Average travel distances of each mode taken for the short-distance trip [16].

In total, 16 studies were reviewed, with 12 factors, which included socioeconomic factors such as gender, age, household income, and vehicle ownership that were mostly used as explanatory variables. Additionally, trip-related factors such as trip distance, walking comfort, travel time, trip purpose, traffic safety, and traffic condition/congestion were key factors applied in many studies. Some previous studies adopted weather (5 out of 16 studies) and crime (4 out of 16 studies) as explanatory variables. On average, 4.5 explanatory variables were used for 16 reviewed studies.

From this review, two features of the explanatory variables were identified:

(1) Multiple factors were considered for mode choice models

(2) Traditional factors (e.g., travel distance and time) were not always involved in mode choice studies

The mode choice for a short-distance trip may not follow the traditional approaches of mid/long-distance trips. Another reason is that in the short-distance trip, travel distance and time would likely have a minor impact on the choice of mode. Interestingly, these two reasons are correlated so that for short-distance trips other factors largely determine the mode. Travel distance and time are essentially nondeterminants of the transportation mode.

3.4. Takeaways from the Literature Review. There are several key points from the literature review that can be extracted as inputs to analyze the mode choice of travelers for a shortdistance trip:
(1) Many studies have considered up to $5 \mathrm{~km}$ as a shortdistance trip. With this, considering the average speed of walking $(4 \mathrm{~km} / \mathrm{h})[29,30]$ and the average speed of PRT $(40 \mathrm{~km} / \mathrm{h})$ [31], this study adopted $4 \mathrm{~km}$ as a short-distance trip.

(2) Among diverse transportation modes used in a short-distance trip, walking is the most common mode for a short-distance trip. Therefore, two modes being walking and PRT were selected as the alternatives for this study to develop the survey and mode choice models.

(3) Various factors were reviewed as explanatory variables from previous studies. These trip features (e.g., travel time, travel distance, and trip purpose), environmental features (e.g., walking comfort and weather), and individual characteristics (e.g., gender and age) most affected the mode choice for a shortdistance trip. In addition to these factors, the trip purpose, weather condition, PRT fare, travel time, and accompaniment were selected as determinants for the mode choice model in the study.

\section{Methodology}

It is useful to elucidate the overall procedure described in Figure 2. The proposed methodology in this study comprises four parts which consider these objectives:

(1) Undertaking a pilot survey to test the predefined approach

(2) Completing a directional setup with preliminary results for the main survey

(3) Conducting the main survey

(4) Modeling and calibrating the main survey results

The first step was to examine the factors (i.e., explanatory variables) through the pilot survey which were identified from the literature review. Two factors were selected in this step being a weather factor representing traffic environments, and an accompanying children factor which could affect the mode choice in a leisure trip. Note that the major objectives of the pilot survey were checking the applicability of selected factors in this study, and providing preliminary results to be used to set up the main survey.

In considering the weather factor, two different regions comprising large-sized residential areas with parks being 
TABLE 2: Comparison of transportation modes considered regarding a short-distance trip.

\begin{tabular}{|c|c|c|c|c|c|c|c|c|}
\hline \multirow{2}{*}{ Authors } & \multicolumn{7}{|c|}{ Transportation modes } & \multirow{2}{*}{ Number of considered modes } \\
\hline & Walking & Bicycle & Scooter & Taxi & Bus & Subway & Individual vehicle & \\
\hline Mackett [18] & 0 & O & 0 & $\mathrm{O}$ & $\mathrm{O}$ & 0 & 0 & 7 \\
\hline Olszewski and Wibowo [19] & $\mathrm{O}$ & $\mathrm{O}$ & & & O & O & $\mathrm{O}$ & 5 \\
\hline Müller et al. [20] & O & O & O & & O & & $\mathrm{O}$ & 5 \\
\hline Kim and Ulfarsson [13] & $\mathrm{O}$ & $\mathrm{O}$ & & & $\mathrm{O}$ & & $\mathrm{O}$ & 4 \\
\hline Walton and Sunseri [21] & O & & & & & & O & 2 \\
\hline Sidharthan et al. [22] & $\mathrm{O}$ & O & & & & & & 2 \\
\hline Halldórsdóttir et al. [23] & O & O & & & O & & O & 4 \\
\hline Tran et al. [14] & $\mathrm{O}$ & $\mathrm{O}$ & 0 & & & & & 3 \\
\hline Li et al. [15] & O & O & & & & & O & 3 \\
\hline $\mathrm{Pu}$ et al. [16] & $\mathrm{O}$ & O & O & & $\mathrm{O}$ & & & 4 \\
\hline Prato et al. [24] & O & O & & & O & O & O & 5 \\
\hline Frequency & 11 & 10 & 4 & 1 & 7 & 3 & 8 & - \\
\hline
\end{tabular}

Table 3: Factors considered in previous studies of a short-distance trip.

\begin{tabular}{|c|c|c|c|c|c|c|c|c|c|c|c|c|}
\hline & Gender & Age & $\begin{array}{l}\text { Household } \\
\text { income }\end{array}$ & $\begin{array}{l}\text { Vehicle } \\
\text { ownership }\end{array}$ & $\begin{array}{l}\text { Trip } \\
\text { distance }\end{array}$ & $\begin{array}{c}\text { Walking } \\
\text { comfort } \\
\text { (slope/ } \\
\text { stairway) }\end{array}$ & $\begin{array}{l}\text { Travel } \\
\text { time }\end{array}$ & $\begin{array}{l}\text { Trip } \\
\text { purpose }\end{array}$ & $\begin{array}{l}\text { Traffic } \\
\text { safety }\end{array}$ & $\begin{array}{c}\text { Traffic } \\
\text { condition/ } \\
\text { congestion }\end{array}$ & Weather & Crime \\
\hline Mackett [18] & 0 & O & & & O & & O & O & & & & \\
\hline $\begin{array}{l}\text { Olszewski and } \\
\text { Wibowo [19] }\end{array}$ & & & & & O & O & & & O & O & & \\
\hline $\begin{array}{l}\text { Müller et al. } \\
\text { [20] }\end{array}$ & & & & O & O & & & & & & $\mathrm{O}$ & \\
\hline $\begin{array}{l}\text { Kim and } \\
\text { Ulfarsson [13] }\end{array}$ & O & O & & & O & & O & & & & & \\
\hline $\begin{array}{l}\text { Walton and } \\
\text { Sunseri [21] }\end{array}$ & O & & & & O & O & O & & & & O & O \\
\hline $\begin{array}{l}\text { Sidharthan } \\
\text { et al. [22] }\end{array}$ & & & O & O & & O & & & O & O & O & \\
\hline $\begin{array}{l}\text { Halldórsdóttir } \\
\text { et al. [23] }\end{array}$ & O & & & O & & O & O & O & & & $\mathrm{O}$ & \\
\hline $\begin{array}{l}\text { Lee et al. [25] } \\
\text { Marguet and }\end{array}$ & & & & & & & & & O & O & & \\
\hline & O & O & O & & & & & O & & & & \\
\hline $\begin{array}{l}\text { Rybarczyk and } \\
\text { Gallagher [27] }\end{array}$ & & & & & O & & & & O & O & & O \\
\hline Tran et al. [14] & O & 0 & O & O & & & & O & O & O & & 0 \\
\hline Li et al. [15] & 0 & 0 & 0 & 0 & & & & & & & & \\
\hline Pu et al. [16] & & 0 & 0 & 0 & & & 0 & 0 & & & & \\
\hline $\begin{array}{l}\text { Ferrer and Ruiz } \\
\text { [17] }\end{array}$ & & & & & & O & & & & & & O \\
\hline $\begin{array}{l}\text { Guang and } \\
\text { Reid [28] }\end{array}$ & & & O & & & O & & & & & & \\
\hline Prato et al. [24] & 0 & 0 & 0 & & & O & 0 & O & & & 0 & \\
\hline Frequency & 8 & 7 & 7 & 6 & 6 & 7 & 6 & 6 & 5 & 5 & 5 & 4 \\
\hline
\end{tabular}

Gwanggyo and Ilsan in Gyeonggi Province, Republic of Korea, were selected. During the pilot survey, autonomous and demand-responsive PRT had been introduced as a new and more practical public transit mode to the respondents for the pilot survey. This PRT is an unmanned mode with a maximum of 6 passengers operating on a designated or virtually marked road where a user can access a ride anytime.

The second step to design the main survey was based on preliminary results from the pilot survey. Basically, two main purposes being mandatory and nonmandatory were considered with two factors, which were tested in the pilot survey, using two different fare schemes. The type of scenarios was accordingly set up with factors that needed to be considered for the model calibration. The next step was to conduct the main survey comprising 60 questions, followed by model calibration and logistic regression. Despite the availability of emerging techniques, such as machine learning methods, the logistic regression model was selected as the tool to analyze the behavior of travelers for short-distance trips.

This decision has two significant reasons: 


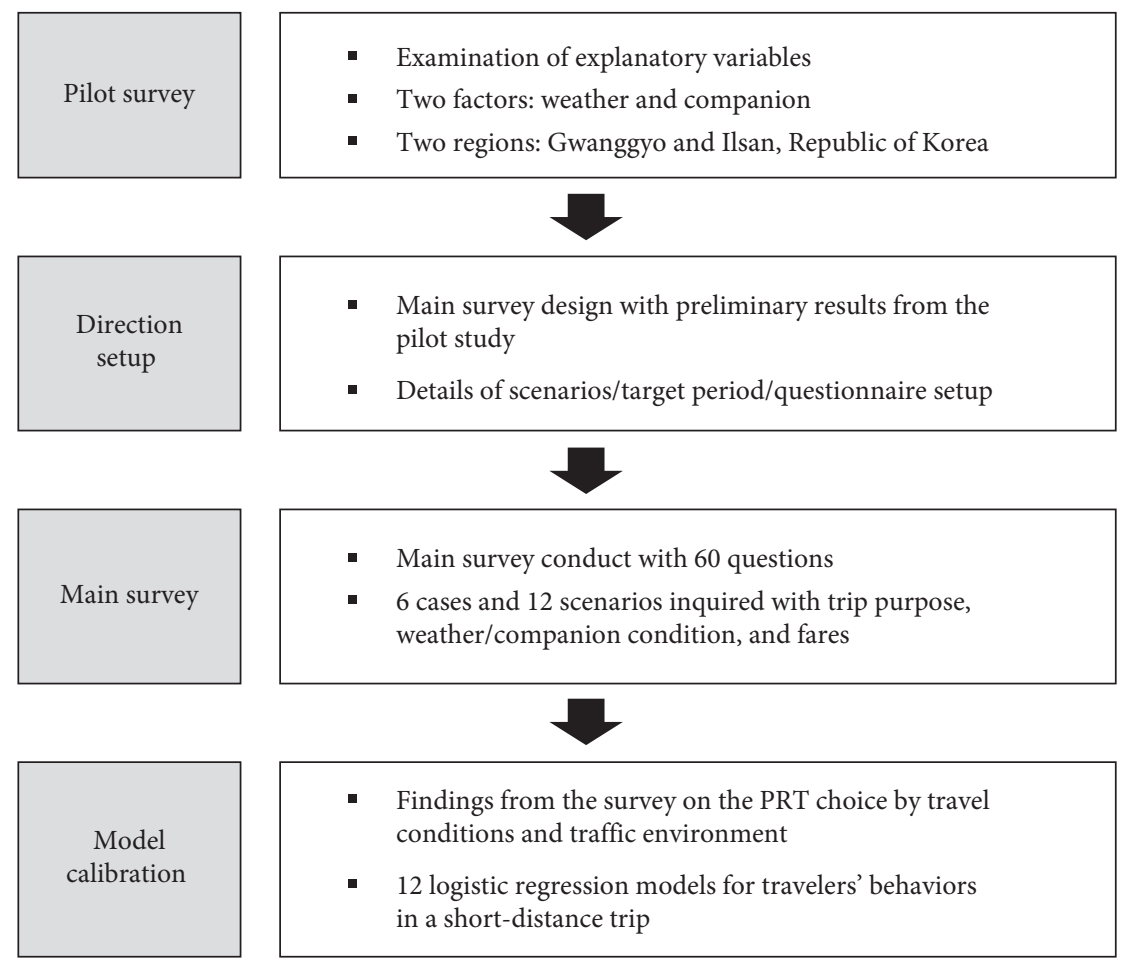

FIgURE 2: Overall procedure of the methodology.

(1) The logistic regression models have been regarded as a standard method for describing the relationship between a response variable and explanatory variables over the last decade [32]

(2) Machine learning techniques are gaining in popularity, but can become inefficient with a relatively small size datasets as it requires massive datasets to train the models [33]

\section{Analysis and Results}

5.1. Pilot Survey: Preliminary Findings for Travelers' Behaviors in Short-Distance Trips. From the pilot survey 1,030 responses were received by surveyors from the two regions ( 515 responses each). However, only 1,006 responses were valid (effectively 97.7\%). The basic question had two choices being good versus bad weather (snow, rain, and/or cold temperatures). In cases where the travel time when walking was within 20 minutes, the intervals for the questionnaire were $5,10,15$, and 20 minutes, with the mode choice being either walking or PRT. The flat fare for PRT was assumed as 500 Korean won (KRW) per person, regardless of the distance traveled. Figure 3(a) describes the result of the pilot survey for the weather condition.

Another location (Uiwang in Gyeonggi Province, Republic of Korea) being a lake park region where family leisure activities frequently occur was chosen to examine the effect of the travelers' companions. A total of 501 valid responses were obtained from nearby the Uiwang subway station and rail bike station. The PRT option was presented in terms of an increase in travel cost from 0 to 1,500 (KRW per person). In this pilot survey, only travel cost was given as a determinant in choosing PRT because the distance between the Uiwang subway station and the rail bike station was fixed at $1 \mathrm{~km}$, and the actual cost for accompanying children had not been confirmed. Figure 3(b) shows the results of this pilot survey.

The pilot survey revealed that travelers preferred PRT when the weather condition was not good, compared to when the weather was obviously good. The relationship between travel time and the weather condition was also observed. As travel time increased, the extent of impacts from the weather condition decreased. If travel time was relatively long, it became a key determinant of choosing PRT regardless of the weather condition. In contrast, when the travel time was relatively short, the weather condition became the crucial factor in selecting PRT. In terms of accompanying children, when the PRT fare was zero, most of the interviewees would choose PRT, but the probability of PRT choice decreased in two distinct cases. This was when the PRT fare increased, or when traveling without children. With a travel cost up to $500 \mathrm{KRW}$ per person, the probabilities for PRT choice showed little difference, regardless of accompanying children.

5.2. Direction Setup for Main Survey: Case Development and Calibration Process. From the pilot survey, 6 cases (see Figure 4) were generated to develop main questionnaires in the survey and eventually to the development of mode choice models.

Six cases were originally generated, with each case having two different fare schemes: 500 and 1,000 KRW per person. Thus, in total, 12 scenarios were considered in this study. Because a mandatory trip rarely occurs with children, the 


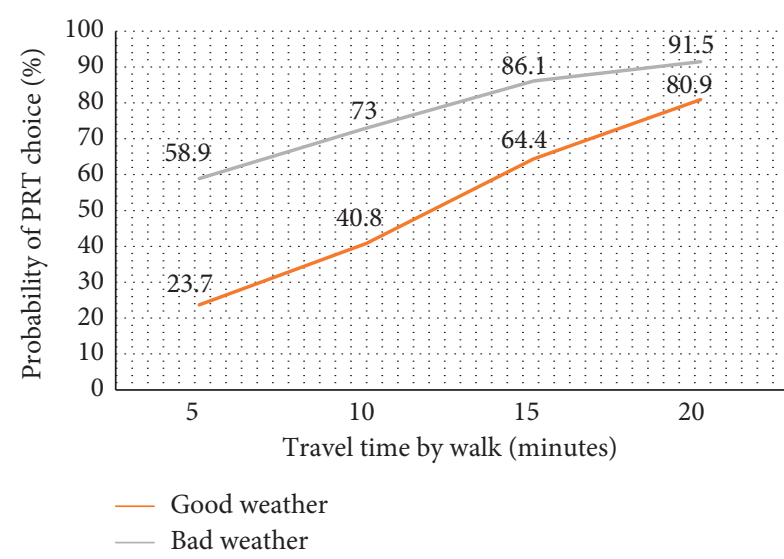

(a)

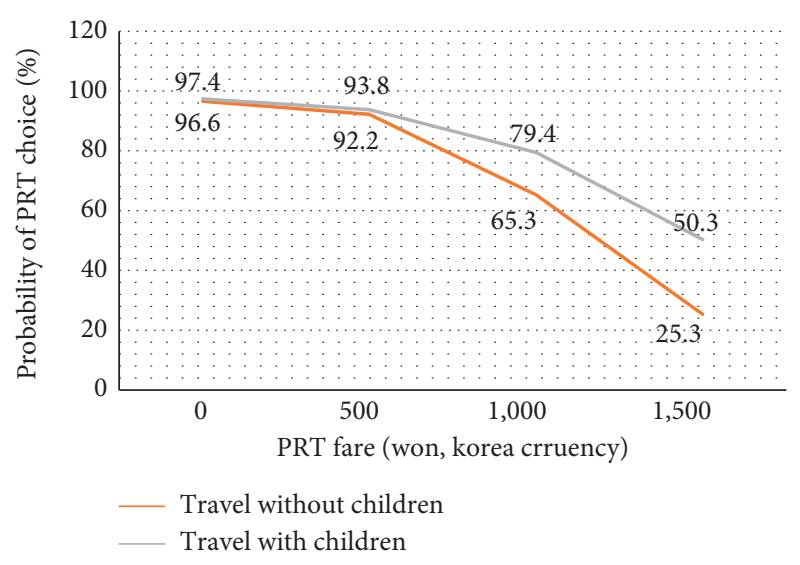

(b)

FIGURE 3: Pilot survey results of weather and companion conditions: (a) weather condition; (b) companion condition (travel with children).

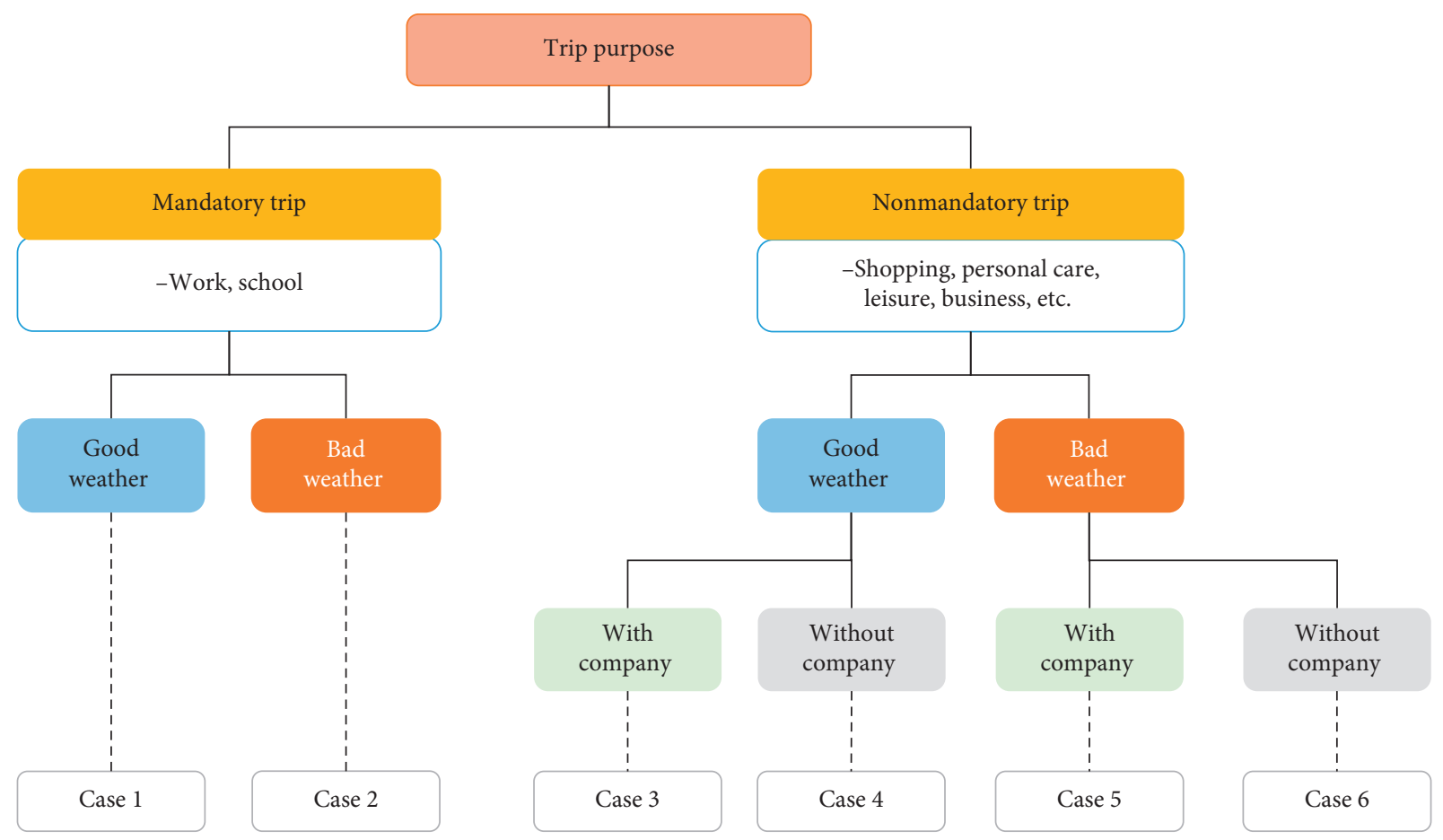

Figure 4: Case tree for mode choice models.

conditions for accompanying children were included only in a nonmandatory trip (see Table 4).

A four-step approach was taken (see Figure 5), of which questionnaires were developed from steps 1 to 3 and step 4 was about how to calibrate the mode choice models in this study:

(1) A total distance of $4 \mathrm{~km}$ was divided into five intervals of 800 meters per each (defined as a shortdistance trip in this study)

(2) Travel distance was selected randomly from each interval
(3) Travel times with walking and PRT, respectively, were estimated from each randomly selected travel distance

(4) At every 100 meters, the probabilities of PRT choice were fitted into the diversion curve

As previously mentioned, 60 questions were posed to each interviewee in the main survey, consisting of six scenarios with two fare options (500 and 1,000 KRW), and five intervals separated by 800 meters (out of $4 \mathrm{~km})$. 
TABLE 4: List of selected cases for mode choice models.

\begin{tabular}{lccc}
\hline Case number & Trip purpose & Weather condition & Companion condition \\
\hline Case 1 & Mandatory & Good & - \\
Case 2 & & Bad & - \\
\hline Case 3 & & Good & No \\
Case 4 & Nonmandatory & Bad & No \\
Case 5 & & Good & Yes \\
Case 6 & & Bad & Yes \\
\hline
\end{tabular}
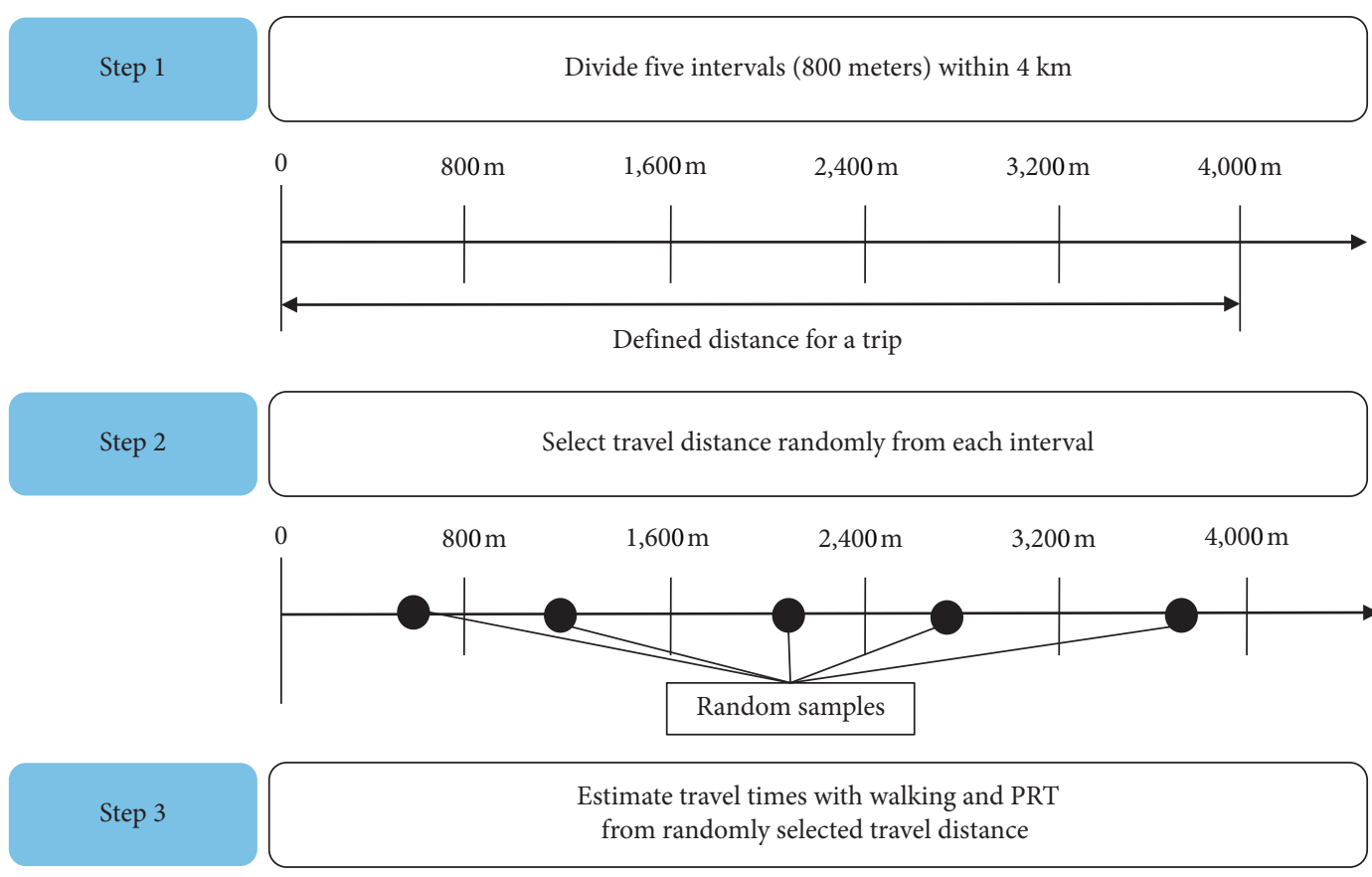

Example question in survey

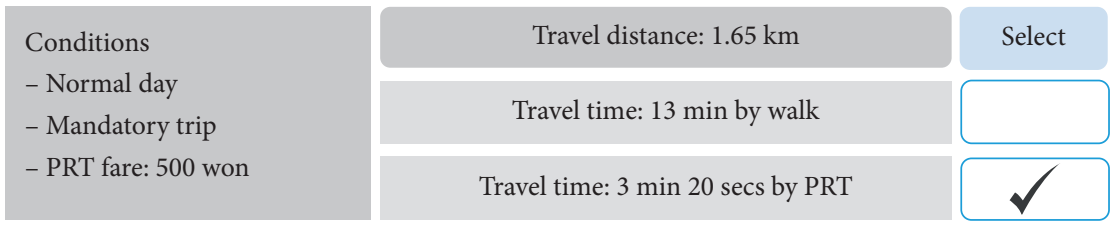

Fit the diversion curve with the probabilities of PRT choice at every 100 meters

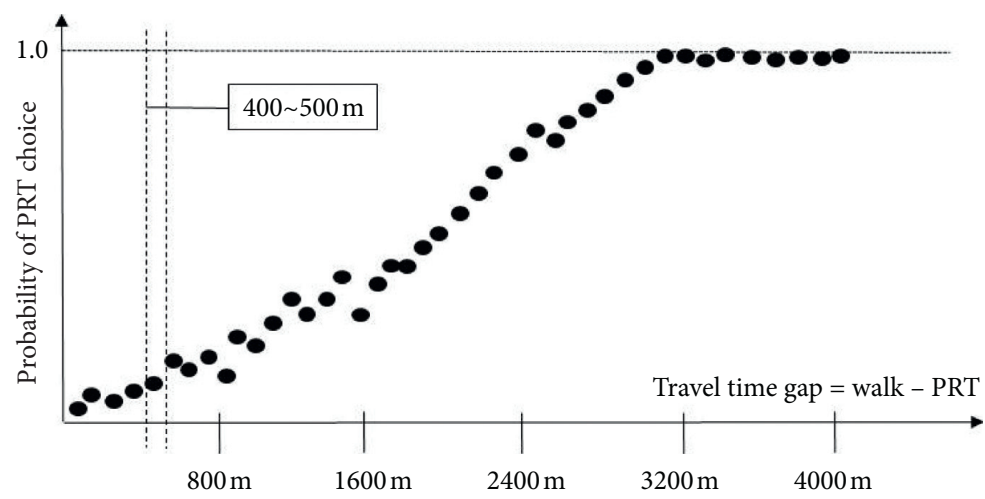

Figure 5: Process of developing mode choice models. 
TABLE 5: Interviewees' characteristics.

\begin{tabular}{lc}
\hline Categories & Frequency (respondent, \%) \\
\hline Gender & $609(50.0)$ \\
Male & $608(50.0)$ \\
Female & \\
\hline Age & $128(10.5)$ \\
$0-19$ & $240(19.7)$ \\
$20-29$ & $239(19.6)$ \\
$30-39$ & $241(19.8)$ \\
$40-49$ & $240(19.7)$ \\
$50-59$ & $129(10.6)$ \\
$60+$ & \\
\hline Occupation & $633(52.1)$ \\
Employee (full-time) & $107(8.8)$ \\
Self-employed individual & $234(19.2)$ \\
Sstudent & $157(12.9)$ \\
Housewife & $54(4.4)$ \\
Unemployed person & $32(2.6)$ \\
Others & \\
\hline Number of family members & $99(8.1)$ \\
1 & $164(13.5)$ \\
2 & $334(27.4)$ \\
3 & $491(40.3)$ \\
4 & $105(8.6)$ \\
5 & $24(2.1)$ \\
$6+$ & \\
\hline Family income (unit: thousand & \\
KRW/month) & $61(5.0)$ \\
$0-999$ & $117(9.6)$ \\
$1,000-1,999$ & $205(16.8)$ \\
$2,000-2,999$ & $236(19.4)$ \\
$3,000-3,999$ & $200(16.4)$ \\
$4,000-4,999$ & $186(15.3)$ \\
$5,000-5,999$ & $85(7.1)$ \\
$6,000-6,999$ & \\
$7,000+$ & \\
\hline & \\
& \\
\hline &
\end{tabular}

\subsection{Main Survey: Results for Travelers' Behaviors in Short-} Distance Trips

5.3.1. Description and Demographic Statistics. The main survey was conducted through the Internet to (1) obtain a significant number of responses for all types of traveler's groups and (2) have more balanced responses regardless of the locational features. 1,217 respondents were interviewed with gender parity for four days (from $30^{\text {th }}$ of September to $3^{\text {rd }}$ of October 2016). Table 5 presents the details of the interviewees' responses.

5.3.2. Description of Logistic Regression Models. On the basis of the main survey, there are preliminary observations regarding the impacts of travel conditions or the traffic environment on choosing PRT, in addition to the calibration of mode choice models, as follows:

(1) In the mandatory trip, (i) PRT was preferred during inclement weather conditions regardless of PRT fares, and (ii) when the PRT fare was lower, travelers obviously preferred to use PRT even during good weather conditions (see Figure 6). To be specific, both scenarios with travel costs of 500 KRW and 1,000 KRW during bad weather (in case 2) showed higher probabilities than case 1 (good weather conditions). However, in case 1 (good weather), a scenario with $500 \mathrm{KRW}$ showed a higher probability than a scenario with 1,000 KRW (see a horizontal axis of 10-minute difference of travel time). If the weather was good, a cheaper PRT fare increased the probability of PRT choice by around $30 \%$ when the travel time was different by 10 minutes.

(2) In the nonmandatory trip without company scenario, the same result was observed. That is, (i) PRT fares did not significantly impact the choice of PRT in bad weather and (ii) a lower fare affected PRT choice with good weather conditions (see Figure 7). In case 4, both scenarios with $500 \mathrm{KRW}$ and 1,000 KRW with bad weather had higher probabilities than case 3 (good weather conditions), whereas with 500 KRW, a higher probability was observed in case 3 compared to the one with 1,000 KRW (being an approximate $15 \%$ gap in 18 -minute difference of travel time between $500 \mathrm{KRW}$ and 1,000 KRW).

(3) When comparing a mandatory trip against a nonmandatory trip without company with a $500 \mathrm{KRW}$ fare, the nonmandatory trip without company was more sensitive to weather conditions as shown in the left graphs in Figures 6 and 7. This sensitivity became similar with a 1,000 KRW fare (see the right graphs in Figures 6 and 7). That is, the decision for PRT was obviously affected by weather conditions in both a mandatory trip and nonmandatory trip without company.

(4) In the nonmandatory trip with company, (i) the weather condition made a difference to the probability of a PRT choice regardless of fares and (ii) the impact of differing fares showed a minor difference under the same weather conditions both in cases 5 and 6 (see Figure 8). Specifically, with company, having bad weather conditions was a valid factor to determine the choice of PRT. As indicated in Figure 8 , a gap of around $30 \%$ of 9 -minute difference of travel time between bad and good weather conditions (in cases 5 and 6) was found in both fares. As shown in a horizontal axis of 15 -minute difference of travel time with bad weather, similar probabilities were observed. This was regardless of the fare difference which led to the conclusion that trips with company were not affected by fares, but rather, by weather conditions.

(5) Under good weather conditions, (i) differing fares influenced the choice of PRT regardless of trip purposes and (ii) the trip purpose affected PRT choice, particularly with a lower fare (see Figure 9). That is, with the same trip purpose, the probability of choosing PRT with $500 \mathrm{KRW}$ was generally higher than the one with 1,000 KRW. Looking at the horizontal axis of 15-minute difference of travel 

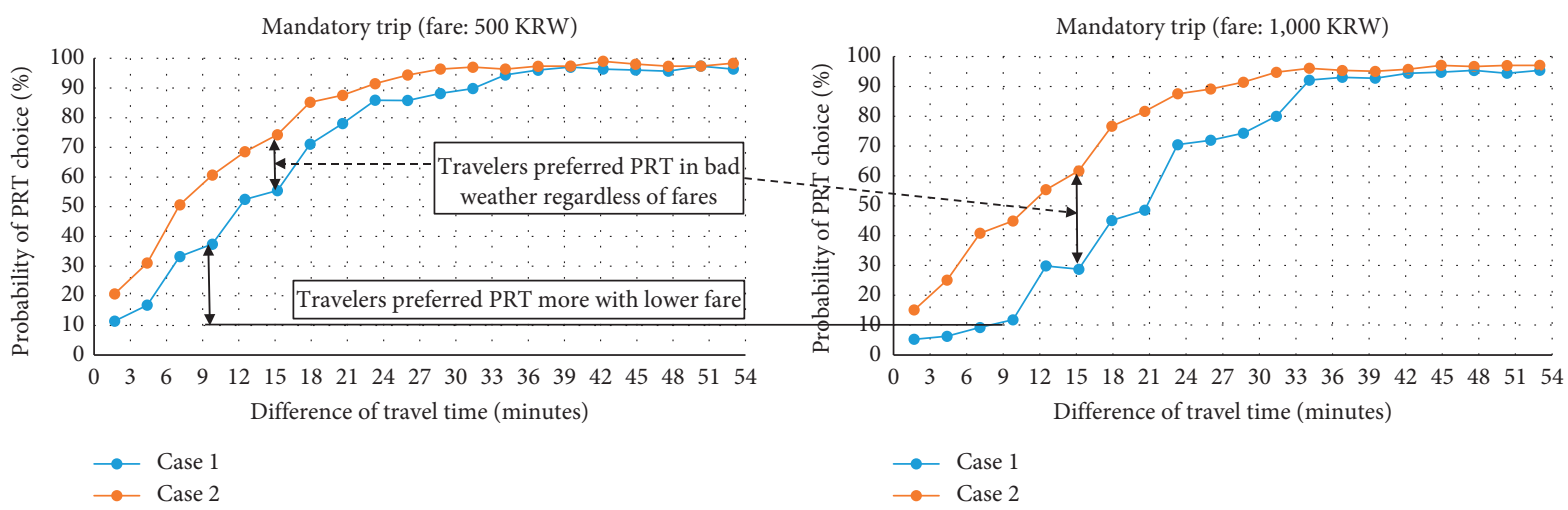

(a)

(b)

FIgURE 6: Impacts by weather and fare on PRT choice in the mandatory trip.
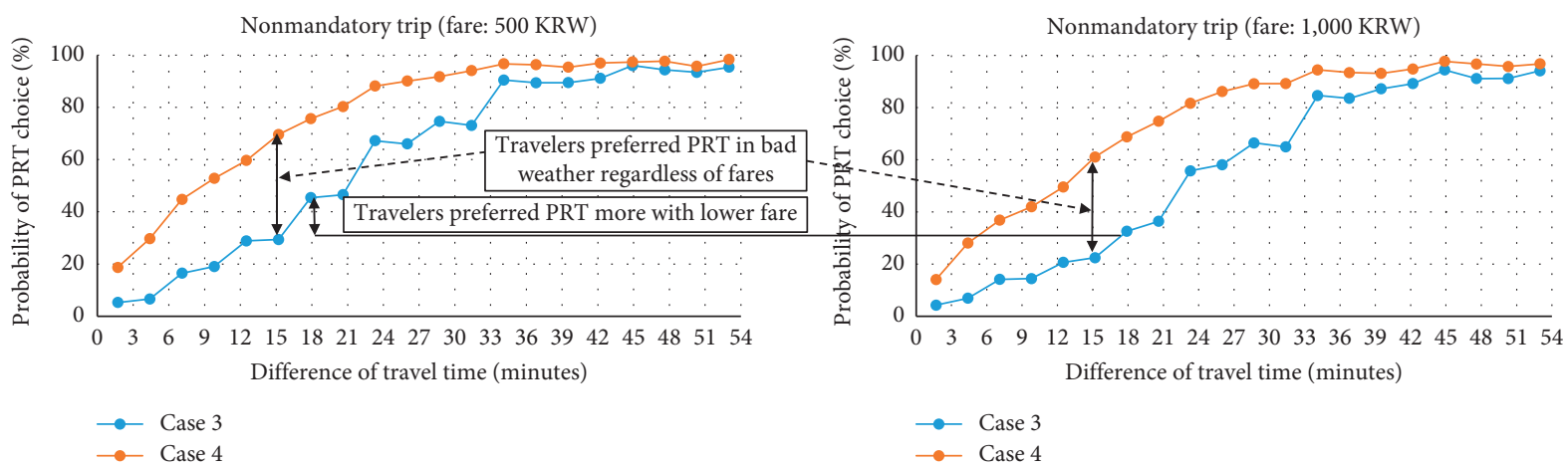

(a)

(b)

FIgURE 7: Impacts by weather and fare on PRT choice in the nonmandatory trip without company.

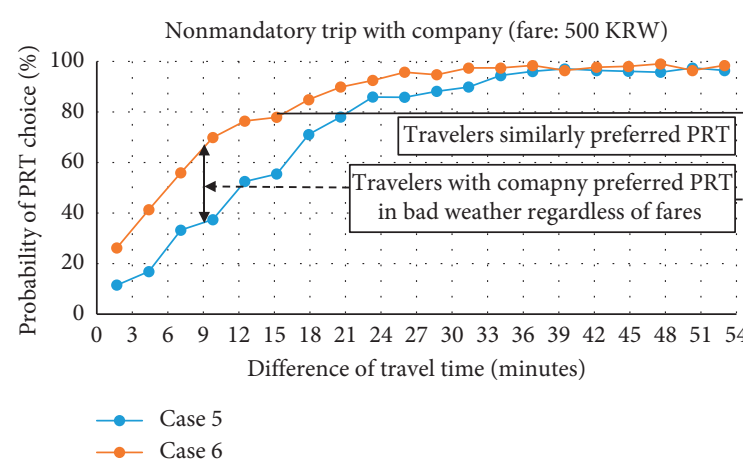

(a)

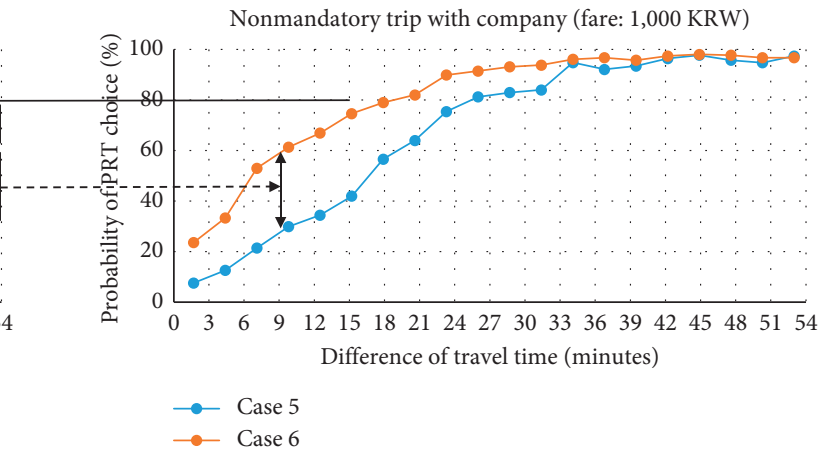

(b)

FIGURE 8: Impacts by weather and fare on PRT choice in the nonmandatory trip with company.

time, the probability of PRT choice in a mandatory trip with $500 \mathrm{KRW}$ was higher by around $25 \%$ than the one with 1,000 KRW. Also, with different trip purpose, the probability of PRT choice for the mandatory trip was always higher than for nonmandatory trips owing to the higher value placed on time by those who need to travel obligatorily.
(6) Under bad weather conditions, (i) the fare difference was not a strong factor to determine the choice of PRT regardless of trip purposes and (ii) the trip purpose did not affect the choice of PRT strongly (see Figure 10). With the same trip purpose, a similarity was found in terms of the probabilities of choosing PRT from the two fares. Likewise, with the same fare condition, the probabilities of PRT choice became 


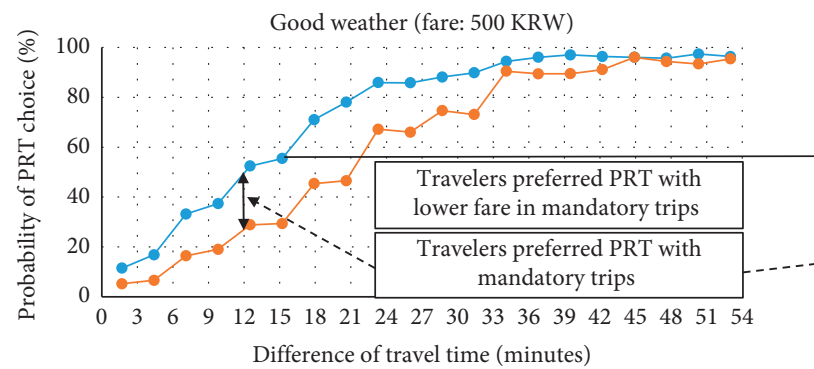

$\rightarrow$ Case 1

$\rightarrow$ Case 3

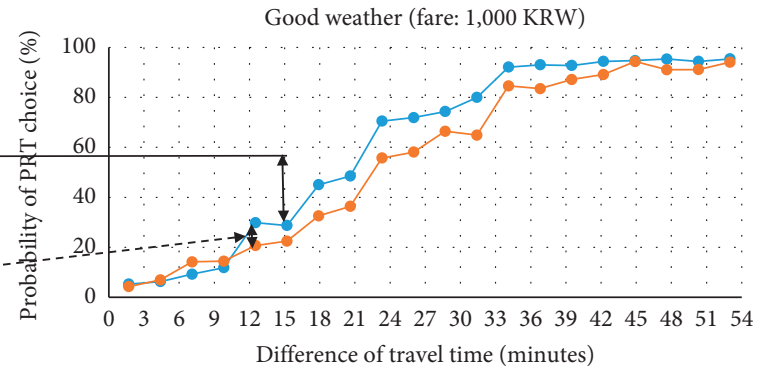

$\longrightarrow$ Case 1

$\rightarrow$ Case 3 (b)

FIGURE 9: Impacts by fare and trip purpose on PRT choice under good weather conditions.

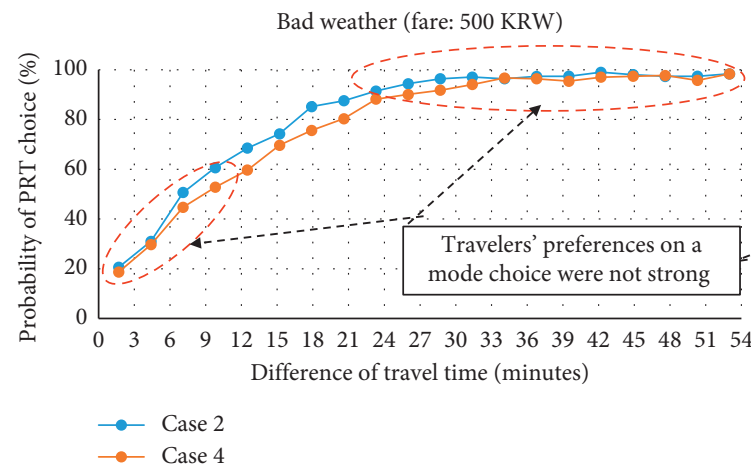

(a)

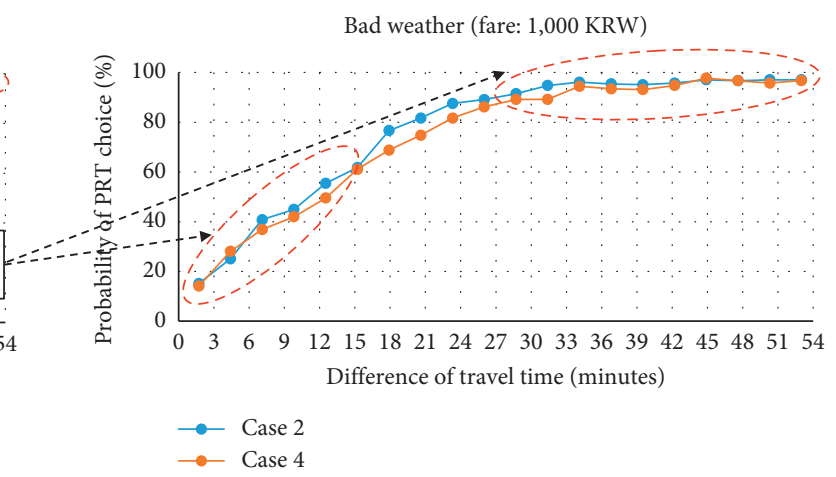

(b)

FIgURE 10: Impacts by fare and trip purpose on PRT choice under bad weather conditions.

TABLE 6: Logistic regression models for 12 scenarios.

\begin{tabular}{|c|c|c|c|c|c|c|}
\hline Cases & Scenarios & Trip purpose & $\begin{array}{l}\text { Weather } \\
\text { condition }\end{array}$ & $\begin{array}{l}\text { Companion } \\
\text { condition }\end{array}$ & $\begin{array}{l}\text { PRT fare } \\
\text { (KRW) }\end{array}$ & Functions \\
\hline \multirow{3}{*}{ Case 1} & Scenario 1 & & \multirow{3}{*}{ Good } & \multirow{3}{*}{-} & 500 & $p=\frac{\exp (-1.651+0.126 \times \text { difference of travel time })}{1+\exp (-1.651+0.126 \times \text { difference of travel time })}$ \\
\hline & & & & & & $D=\exp (-2.831+0.137 \times$ difference of travel time $)$ \\
\hline & Scenario 2 & Mandatory & & & 1,000 & $P=\frac{1}{1+\exp (-2.831+0.137 \times \text { difference of travel time })}$ \\
\hline \multirow{2}{*}{ Case 2} & Scenario 3 & Thatidatory & \multirow{2}{*}{$\mathrm{Bad}$} & \multirow{2}{*}{-} & 500 & $p=\frac{\exp (-1.034+0.133 \times \text { difference of travel time })}{1+\exp (-1.034+0.133 \times \text { difference of travel time })}$ \\
\hline & Scenario 4 & & & & 1,000 & $p=\frac{\exp (-1.344+0.122 \times \text { difference of travel time })}{1+\exp (-1.344+0.122 \times \text { difference of travel time })}$ \\
\hline \multirow[b]{2}{*}{ Case 3} & Scenario 5 & & \multirow[b]{2}{*}{ Good } & \multirow[b]{2}{*}{ No } & 500 & $p=\frac{\exp (-2.548+0.122 \times \text { difference of travel time })}{1+\exp (-2.548+0.122 \times \text { difference of travel time })}$ \\
\hline & Scenario 6 & & & & 1,000 & $p=\frac{\exp (-2.825+0.117 \times \text { difference of travel time })}{1+\exp (-2.825+0.117 \times \text { difference of travel time })}$ \\
\hline \multirow[b]{2}{*}{ Case 4} & Scenario 7 & & \multirow[b]{2}{*}{ Bad } & \multirow[b]{2}{*}{ No } & 500 & $p=\frac{\exp (-1.139+0.119 \times \text { difference of travel time })}{1+\exp (-1.139+0.119 \times \text { difference of travel time })}$ \\
\hline & Scenario 8 & Nonmandatory & & & 1,000 & $p=\frac{\exp (-1.365+0.111 \times \text { difference of travel time })}{1+\exp (-1.365+0.111 \times \text { difference of travel time })}$ \\
\hline \multirow[b]{2}{*}{ Case 5} & Scenario 9 & & \multirow[b]{2}{*}{ Good } & \multirow[b]{2}{*}{ Yes } & 500 & $p=\frac{\exp (-2.001+0.134 \times \text { difference of travel time })}{1+\exp (-2.001+0.134 \times \text { difference of travel time })}$ \\
\hline & Scenario 10 & & & & 1,000 & $p=\frac{\exp (-2.182+0.128 \times \text { difference of travel time })}{1+\exp (-2.182+0.128 \times \text { difference of travel time })}$ \\
\hline \multirow{2}{*}{ Case 6} & Scenario 11 & & \multirow{2}{*}{ Bad } & \multirow{2}{*}{ Yes } & 500 & $p=\frac{\exp (-0.657+0.122 \times \text { difference of travel time })}{1+\exp (-0.657+0.122 \times \text { difference of travel time })}$ \\
\hline & Scenario 12 & & & & 1,000 & $p=\frac{\exp (-0.826+0.112 \times \text { difference of travel times })}{1+\exp (-0.826+0.112 \times \text { difference of travel time })}$ \\
\hline
\end{tabular}




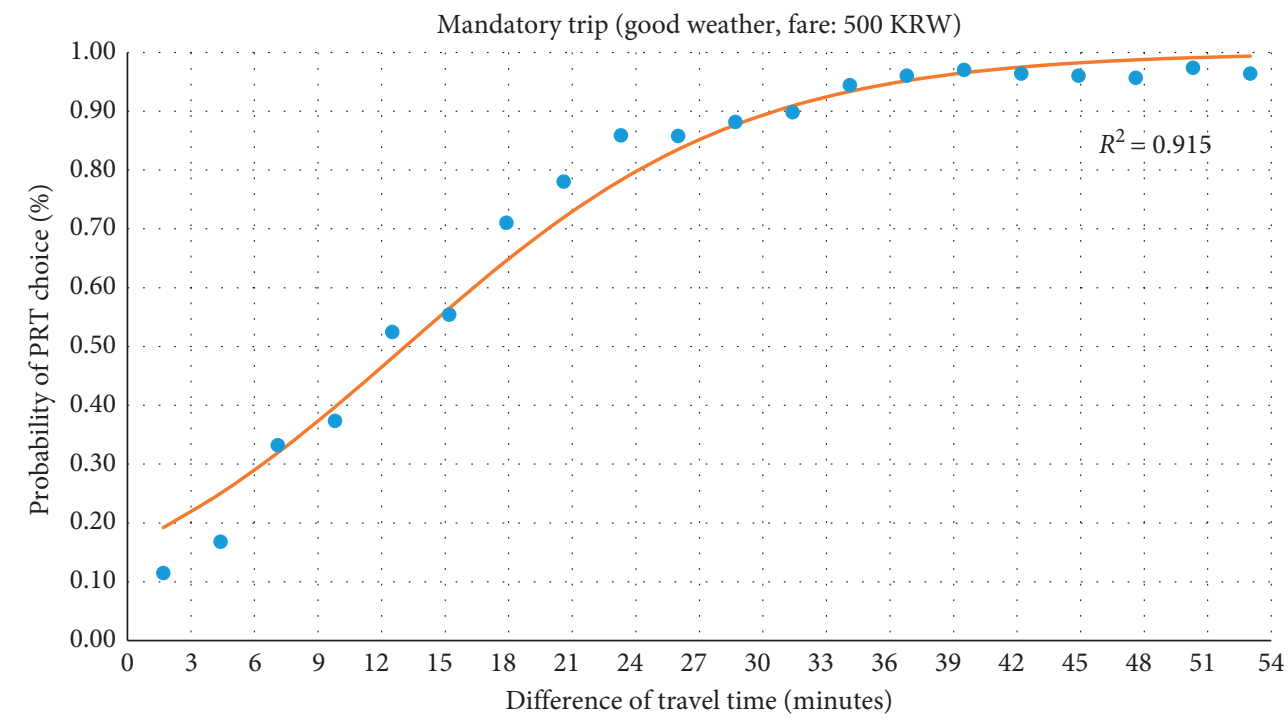

- Case 1: observed

— Logistic: estimated

FIGURE 11: Logistic regression curve of the mandatory trip with $500 \mathrm{KRW}$ under good weather (scenario 1).

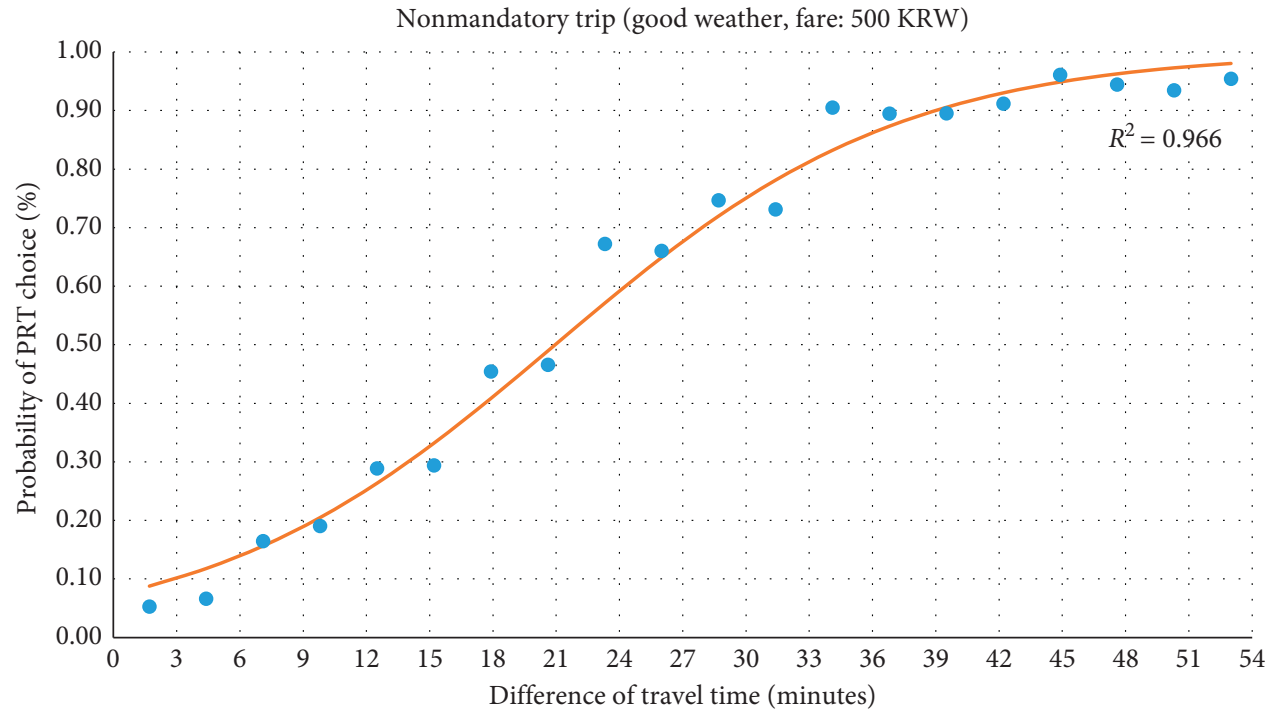

- Case 3: observed

L Logistic: estimated

FIGURE 12: Logistic regression curve of the nonmandatory trip with $500 \mathrm{KRW}$ under good weather (scenario 5).

similar on both mandatory and nonmandatory trips without company.

5.4. Model Calibration: Logistic Regression Models for Travelers' Behaviors in Short-Distance Trips. Based on the results from the main survey, the probability function for PRT choice was calibrated. After testing a variety of functions, a logistic regression curve was determined because of its high goodness-of-fit. In total, 12 logistic regression curves are presented in Table 6 .
Among the 12 scenarios, two examples have been presented based on the observed data from the main survey and calculated values from logistic regression functions 1 and 5 . The R-squared measures per each model showed high goodness-offits which were 0.915 (Figure 11) and 0.966 (Figure 12), respectively.

\section{Conclusions}

There are emerging demands for connectivity of the first and last mile of travel. According to the advancement of ICT and 
growing interest in environmental issues, special transportation modes in short-distance trips that satisfy an individual's various needs for convenience and comfort have been identified. Previous studies have mostly dealt with mid/ long-distance trips due in part to the lack of suitable models or usable data for the short-distance trip. Some studies that have focused on short-distance trips conducted a simple analysis and were limited in scope.

The main features of the current study are

(1) to propose a suitable approach that can understand the features determining mode choice of transportation for a short-distance trip;

(2) to quantify the impact of various factors, including the trip purpose, weather condition, fare, travel time, and accompanying children, which affect the mode choice for a short-distance trip;

(3) to reaffirm the applicability of the logistic regression model for the analysis of traveler's behavior for a short-distance trip; and

(4) to provide the groundwork for the analysis of active transportation modes, such as electric scooters, which are expected to grow in response to new demands (including Mobility-as-a-Service) for the short-distance trip.

In conclusion, the trip purpose and weather condition impacted as factors on the mode choice being consistent in part with Ashkrof et al. [34]. For a mandatory workplace or school trip under similar travel times, travelers preferred PRT. A preference for PRT was also observed in bad weather conditions, regardless of the type of trip purposes and PRT fares. When traveling with company, the weather condition became a key factor again in choosing PRT, while the variation of fares did not comparatively have an impact on mode choice. In summary, when the weather was not good, PRT fare difference and trip purposes were not a strong factor when deciding to choose PRT. However, during good weather, other factors contributed to the choice of PRT. These included differing fares regardless of trip purposes, and the trip purpose (i.e., mandatory trips) affected PRT choice, particularly with a lower fare. Given that fares become an effective factor under good weather conditions, this finding is also similar to the one from Liu et al. [35] who concluded that cost significantly influenced mode choice for short-distance trips.

The weather has a significant effect on our lives. For example, the average number of days with precipitation (including snowfall and rainfall) is 103.5 days per year in the Republic of Korea [36]. As such, the extent of the impact of weather conditions on PRT choice is noteworthy. This might require further careful and thorough investigation because of the recent spotlight on diverse environmental factors, such as global warming, climate change, yellow dust, and fine dust.

In comparison to previous disaggregated behavioral models (e.g., logit models), this study employed a logistic regression model to calibrate the outputs from the survey. Note that the short-distance trip is less affected by travel deterrents such as travel time, distance, and fares, when compared with the long-distance trip. However, various other factors, such as weather, security, and slope, determine mode choice for the short-distance trip. Because a logit model requires many explanatory variables, the process of calibration becomes complicated, which in turn defines the model's explanatory significance as low.

To overcome this problem, an alternative model considering diverse variables for mode choice was developed by using a logistic regression model, which replicated actual mode choice from the survey. Nevertheless, as the logistic regression model has a limitation when expressing more than three multiple modes, alternative approaches need to be considered. These include machine learning techniques that can incorporate a number of factors and modes together. In this aspect, decision analysis techniques, such as the conjoint method, Naïve Bayes algorithm decision tree algorithm, or random forest algorithm, can be options used for mode choice modeling with various explanatory factors within future studies.

\section{Data Availability}

All data used in this study are available upon request to the author (Hyunmyung Kim, khchlsy@gmail.com).

\section{Disclosure}

Changju Lee is currently at Transport Division, United Nations Economic and Social Commission for Asia and the Pacific, Bangkok 10200, Thailand. The views expressed herein are those of the authors and do not necessarily reflect the views of the United Nations.

\section{Conflicts of Interest}

The authors declare that there are no conflicts of interest regarding the publication of this paper.

\section{Acknowledgments}

This study was supported by a grant from R\&D program of the Korea Railroad Research Institute, Republic of Korea. In addition, the improvement of this study was supported by Basic Science Research Program through the National Research Foundation of Korea funded by the Ministry of Science, ICT, and Future Planning (no. 2016R1A2B2012722).

\section{References}

[1] C. A. Klöckner and T. Friedrichsmeier, "A multi-level approach to travel mode choice-how person characteristics and situation specific aspects determine car use in a student sample," Transportation Research Part F: Traffic Psychology and Behaviour, vol. 14, no. 4, pp. 261-277, 2011.

[2] A. Reichert and H. R. Christian, "Mode use in long-distance travel," The Journal of Transportation and Land Use, vol. 8, no. 2, pp. 87-105, 2015.

[3] A. L. L. Olsson, Factors that Influence Choice of Travel Mode in Major Urban Areas: The Attractiveness of Park \& Ride, 
Infrastruktur, Stockholm, Sweden, 2003, http://urn.kb.se/ resolve?urn=urn:nbn:se:kth:diva- 1627.

[4] Minal and C. R. Sekhar, "Mode choice analysis: the data, the models and future ahead," International Journal for Traffic and Transport Engineering, vol. 4, no. 3, pp. 269-285, 2014.

[5] M. Spies, "Distance between home and workplace as a factor for job satisfaction in the North-West Russian oil industry," Fennia, vol. 184, no. 2, pp. 133-149, 2006.

[6] R. Ewing, W. Schroeer, and W. Greene, "School location and student travel: analysis of factor affecting mode choice," Journal of the Transportation Research Board, vol. 1895, no. 1, pp. 55-63, 2004.

[7] United Nations Framework Convention on Climate Change, The Paris Agreement, United Nations Framework Convention on Climate Change, New York, NY, USA, 2019, https:// unfccc.int/process-and-meetings/the-paris-agreement/theparis-agreement.

[8] L. Ming, H. Zhu, L. Xia, and L. Lei, "Intercity travel demand analysis model," Advances in Mechanical Engineering, vol. 6, Article ID 108180, 2015.

[9] Institute for Transportation and Development Policy, "Escooters could be a last-mile solution for everyone," Transport Matters, Institute for Transportation and Development Policy, New York, NY, USA, 2019, https://www.itdp.org/2018/12/14/ e-scooters-last-mile-solution/.

[10] A. Singh, Uber Electric Scooters for Affordable Last-Mile Connectivity: What They Are and Will They Come to India, Financial Express, Noida, India, 2019, https://www.financialexpress. com/auto/bike-news/uber-electric-scooters-for-affordablelast-mile-connectivity-what-they-are-and-will-they-cometo-india/1530478/.

[11] R. Moeckel, R. Fussell, and R. Donnelly, "Mode choice modeling for long-distance travel," Transportation Letters, vol. 7, no. 1, pp. 35-46, 2015.

[12] C. Llorca, J. Molloy, J. Ji, and R. Moeckel, "Estimation of a long-distance travel demand model using trip surveys, location-based big data, and trip planning services," Transportation Research Record: Journal of the Transportation Research Board, vol. 2672, no. 47, pp. 103-113, 2018.

[13] S. Kim and G. F. Ulfarsson, "Curbing automobile use for sustainable transportation: analysis of mode choice on short home-based trips," Transportation, vol. 35, no. 6, pp. 723-737, 2008.

[14] M. T. Tran, M. Chikaraishi, Q. H. Pham, J. Zhang, and A. Fujiwara, "Effects of perceived neighborhood walkability on mode choice of short-distance trips in Hanoi city," Journal of the Eastern Asia Society for Transportation Studies, vol. 11, pp. 1328-1345, 2015.

[15] M. Li, G. Song, Y. Cheng, and L. Yu, "Identification of prior factors influencing the mode choice of short distance travel," Discrete Dynamics in Nature and Society, vol. 2015, Article ID 795176, 9 pages, 2015.

[16] X. Pu, W. Wang, and Y. Wu, "Short-distance Trip Mode Choice Behavior of the Elderly," in Proceedings of the 15th COTA International Conference Of Transportation, pp. 3854-3865, Beijing, China, July 2015.

[17] S. Ferrer and T. Ruiz, "The impact of the built environment on the decision to walk for short trips: evidence from two Spanish cities," Transport Policy, vol. 67, pp. 111-120, 2018.

[18] R. L. Mackett, "Why do people use their cars for short trips?" Transportation, vol. 30, no. 3, pp. 329-349, 2003.

[19] P. Olszewski and S. Wibowo, "Using equivalent walking distance to assess pedestrian accessibility to transit stations in
Singapore," Journal of the Transportation Research Board, vol. 1927, pp. 38-45, 2005.

[20] S. Müller, S. Tscharaktschiew, and K. Haase, "Travel-to-school mode choice modelling and patterns of school choice in urban areas," Journal of Transport Geography, vol. 16, no. 5, pp. 342-357, 2008.

[21] D. Walton and S. Sunseri, "Factors influencing the decision to drive or walk short distances to public transport facilities," International Journal of Sustainable Transportation, vol. 4, no. 4, pp. 212-226, 2010.

[22] R. Sidharthan, C. R. Bhat, R. M. Pendyala, and K. G. Goulias, A Model of Children's School Travel Mode Choice Behavior Accounting for Spatial and Social Interaction Effects, The University of Texas at Austin, Austin, TX, USA, 2010.

[23] K. Halldórsdóttir, L. Christensen, T. C. Jensen, and C. G. Prato, "Modelling mode choice in short trips-shifting from car to bicycle," in Proceedings of the European Transport Conference, Glasgow, UK, 2011.

[24] C. G. Prato, K. Halldórsdóttir, and O. A. Nielsen, "Latent lifestyle and mode choice decisions when travelling short distances," Transportation, vol. 44, no. 6, pp. 1343-1363, 2017.

[25] C. Lee, X. Zhu, J. Yoon, and J. W. Varni, "Beyond distance: children's school travel mode choice," Annals of Behavioral Medicine, vol. 45, no. 1, pp. 55-67, 2013.

[26] O. Marquet and C. Miralles-Guasch, "Walking short distances. The socioeconomic drivers for the use of proximity in everyday mobility in Barcelona," Transportation Research Part A: Policy and Practice, vol. 70, pp. 210-222, 2014.

[27] G. Rybarczyk and L. Gallagher, "Measuring the potential for bicycling and walking at a metropolitan commuter university," Journal of Transport Geography, vol. 39, pp. 1-10, 2014.

[28] T. Guang and E. A. Reid, "Walk trip generation model for Portland, OR," Transportation Research Part D, vol. 52, pp. 340-353, 2017.

[29] G. Chiaranda, E. Bernardi, L. Codecà et al., "Treadmill walking speed and survival prediction in men with cardiovascular disease: a 10-year follow-up study," BMJ Open, vol. 3, no. 10, 2013.

[30] M.-C. Chiu, H.-C. Wu, and L.-Y. Chang, "Gait speed and gender effects on center of pressure progression during normal walking," Gait \& Posture, vol. 37, no. 1, pp. 43-48, 2013.

[31] D. Jeffery, Guidelines for Implementers of Personal Rapid Transit (PRT), European Commission, Brussels, Belgium, 2010.

[32] J. Fang, "Why logistic regression analyses are more reliable than multiple regression analyses," Journal of Business and Economics, vol. 4, no. 7, pp. 620-633, 2013.

[33] P. Gulhane and B. V. Chaudhari, "Study of machine learning and deep learning of various factors," International Journal of Research in Computer \& Information, vol. 4, no. 3, pp. 16-21, 2019.

[34] P. Ashkrof, G. Homem de Almeida Correia, O. Cats, and B. van Arem, "Impact of automated vehicles on travel mode preference for different trip purposes and distances," Transportation Research Record: Journal of the Transportation Research Board, vol. 2673, no. 5, pp. 607-616, 2019.

[35] Y. Liu, J. Chen, W. Wu, and J. Ye, "Typical combined travel mode choice utility model in multimodal transportation network," Sustainability, vol. 11, no. 2, p. 549, 2019.

[36] Korea Meteorological Administration, Average Number of Days with Precipitation, Korea Meteorological Administration, Seoul, South Korea, 2017, https://data.kma.go.kr/stcs/ grnd/grndRnDay.do?pgmNo=156. 